\title{
Asparagine synthetase expression and its potential prognostic value in patients with $\mathrm{NK} / \mathrm{T}$ cell lymphoma
}

\author{
YAQING LI ${ }^{1}$, XUDONG ZHANG ${ }^{1}$, TENGPENG HU ${ }^{1}$, LIJUAN HAN ${ }^{1}$, \\ RUPING LI ${ }^{1}$, JIANGUO WEN ${ }^{2}$ and MINGZHI ZHANG ${ }^{1}$ \\ ${ }^{1}$ Lymphoma Diagnosis and Treatment Center, Department of Oncology, and ${ }^{2}$ The Institute of Clinical Medicine, \\ The First Affiliated Hospital of Zhengzhou University, Zhengzhou, Henan 450052, P.R. China
}

Received February 21, 2014; Accepted April 4, 2014

DOI: $10.3892 /$ or.2014.3237

\begin{abstract}
Natural killer (NK)/T cell lymphoma usually shows a highly aggressive clinical course and the overall prognosis is poor. At present, there are no standard therapeutic regimens for this disease. Although chemotherapeutic protocols containing L-asparaginase (L-Asp) or pegaspargase (PEG-Asp) have improved the efficacy of treatment, some patients are resistant to L-Asp or PEG-Asp. Previous studies demonstrated that the elevated expression of asparagine synthetase (ASNS) is correlated with the resistance to L-Asp or PEG-Asp and may also affect the prognosis in some types of tumors, but the expression level and clinical significance of ASNS in NK/T cell lymphoma remain unknown. Therefore, we investigated the expression and clinical significance of ASNS in lymphoma cell lines and patients with NK/T cell lymphoma. Firstly, we detected PEG-Asp and L-Asp activity using MTT assay and expression of ASNS using real-time PCR in the 7 lymphoma cell lines. Secondly, we used branched DNA-liquidchip technology (bDNA-LCT) for detecting ASNS mRNA in formalin-fixed, paraffin-embedded tissue sections in 50 cases of NK/T cell lymphoma and in 12 cases of nasal polyps and chronic rhinitis. Moreover, we analyzed the correlations between the expression of ASNS and the sensitivity to L-Asp and PEG-Asp in 7 lymphoma cell lines and with clinicopathological features and prognosis of NK/T cell lymphoma patients who used chemotherapy containing L-Asp and PEG-Asp. There was a marked difference in the sensitivity to L-Asp and PEG-Asp of the 7 lymphoma cell lines. YTS and SNK-6 cells were highly sensitive to PEG-Asp and had relatively low levels of ASNS mRNA expression. Hut-78, Jurkat and Karpas 299 cells were naturally resistant to PEG-Asp, and the ASNS expression levels were extremely high. The expression level of
\end{abstract}

Correspondence to: Professor Mingzhi Zhang, Lymphoma Diagnosis and Treatment Center, Department of Oncology, The First Affiliated Hospital of Zhengzhou University, 1 Jianshe Road, Zhengzhou, Henan 450052, P.R. China

E-mail: mingzhi_zhang1@163.com

Key words: bDNA-LCT, NK/T cell lymphoma, prognostic value, asparagine synthetase, pegaspargase
ASNS was relatively low in the NK/T cell lymphoma tissue compared to levels in the nasal polyps and chronic rhinitis $(0.480 \pm 0.307$ vs. $0.739 \pm 0.267 ; \mathrm{P}=0.009)$. ASNS expression level was associated with III-IV tumor stage $(\mathrm{P}=0.041)$ and a high International Prognostic Index $(\mathrm{P}=0.018)$ in patients with NK/T cell lymphoma. The NK/T cell lymphoma patients with higher ASNS expression had a reduced median survival time when compared with the survival of patients with low ASNS expression $(\mathrm{P}=0.033)$. Cox regression test showed that the ASNS expression level is an independent prognostic factor for $\mathrm{NK} / \mathrm{T}$ cell lymphoma patients. In conclusion, the expression of ASNS was closely related with the sensitivity of lymphoma cell lines to L-Asp and PEG-Asp in vitro and also had a certain effect on the survival of NK/T cell lymphoma patients. In conclusion, high ASNS expression in NK/T cell lymphoma is correlated with worse clinicopathological features.

\section{Introduction}

Natural killer (NK)/T cell lymphoma usually shows a highly aggressive clinical course and is much more common in Asian and Latin American countries than in Western countries (1). The overall prognosis of this disease is poor due to frequent relapse or resistance to treatment $(2,3)$. The response of NK/T cell lymphoma to combined radiotherapy and chemotherapy is usually frustratingly inadequate (4). What is more, most patients initially have low International Prognostic Index (IPI) scores, as they usually present with localized disease involving the head and neck with good performance status $(5,6)$.

Although the treatment of NK/T cell lymphoma has improved greatly, there are no standard therapeutic regimens for this disease. L-asparaginase (L-Asp) and pegaspargase (PEGAsp) are important chemotherapeutic drugs for childhood acute lymphoblastic leukemia (ALL), and clinical trials have also shown that L-Asp treatment improves the outcome of NK/T cell lymphoma (7). The exact molecular events that cause cell death following L-Asp treatment remain unknown. However, suppression of protein synthesis is an obvious potential target and it has been documented that L-Asp exposure initiates the apoptosis of cells (8). Although the chemotherapeutic protocols containing L-Asp have improved the efficacy of treatment, a number of patients are resistant to L-Asp or PEG-Asp, leading to treatment failure and poor long-term prognosis. 
The asparagine synthetase (ASNS) gene encodes the enzyme that catalyzes the biosynthesis of asparagine from aspartate. This reaction proceeds in an ATP-dependent manner with glutamine serving as the nitrogen source (9). Most tissues contain sufficient ASNS activity to maintain asparagine or the enzyme is upregulated in response to asparagine depletion $(10,11)$. It was reported that primary ALL cells and many ALL cell lines exhibit a particularly low level of ASNS expression $(12,13)$, and therefore, are unusually sensitive to asparagine depletion. Early studies demonstrated that the elevated expression of ASNS was correlated with the resistance of leukemic cells to L-Asp $(14,15)$. Similarly, the expression and the functional significance of ASNS have been investigated in solid tumors. ASNS was considered as a causal, predictive biomarker for L-Asp activity in ovarian cancer cells $(16,17)$. Furthermore, one study also showed that the enhanced expression of ASNS protected pancreatic cancer cells from apoptosis induced by glucose deprivation and cisplatin (18). Recently, some studies found that ASNS is overexpressed in castration-resistant prostate cancer (CRPC) and that depletion of asparagine using ASNS inhibitors may be a novel strategy for targeting CRPC cells (19). Another study showed that the expression of ASNS was an independent factor affecting the survival of HCC patients, and low ASNS expression in HCC was correlated with worse surgical outcomes (20).

However, the expression and the functional roles of ASNS in lymphomas remain unclear, particularly in NK/T cell lymphoma. The significance of the expression level of ASNS in the prognosis of NK/T cell lymphoma patients who undergo chemotherapy containing L-Asp or PEG-Asp has not been reported. Therefore, it is meaningful to identify the level of ASNS expression and investigate its clinical significance in the development of NK/T cell lymphoma.

\section{Materials and methods}

Cell culture. Seven lymphoma cell lines (DOHH2, Hut-78, Jurkat, Karpas 299, Raji, SNK-6 and YTS) were stored in the Lymphoma Diagnosis and Treatment Center of Henan Province in the First Affiliated Hospital. All the cells were cultured in Dulbecco's modified Eagle's medium (DMEM) supplemented with $10 \%$ fetal bovine serum (FBS) at $37^{\circ} \mathrm{C}$ in an atmosphere of $5 \% \mathrm{CO}_{2}$.

Cell proliferation assays. The effect of PEG-Asp on cell growth was determined by measuring 3-(4,5-dimethylthiazol-2-yl)2,5-diphenyltetrazolium bromide (MTT; Sigma) absorbance in living cells. In brief, $1.0 \times 0^{5}$ cells/well were seeded in 96 -well microtiter plates. Following exposure to the designated doses of PEG-Asp for the indicated times, MTT solution [20 $\mu \mathrm{l}: 2 \mathrm{mg} / \mathrm{ml}$ in phosphate-buffered saline (PBS)] was added to each well of 96-well plates. The plates were additionally incubated for $4 \mathrm{~h}$ at $37^{\circ} \mathrm{C}$. Medium was withdrawn from the plates by pipetting, and $200 \mu \mathrm{l}$ DMSO was added to each well to solubilize the formazan crystals. The absorbance was recorded using a Teacan 96-well spectrophotometer at a wavelength of $570 \mathrm{~nm}$.

Quantitative real-time PCR. Cell suspensions of DOHH2, Hut-78, Jurkat, Karpas 299, Raji, SNK-6 and YTS cells (the number of cells were $5 \times 10^{6}$ ) were collected, and the concentra- tion of PEG-Asp at $\mathrm{IC}_{50}$ was used to treat each cell line for $48 \mathrm{~h}$. Total RNAs of the 7 lymphoma cell lines before and after drug treatment were then extracted respectively, and each RNA sample $(3 \mu \mathrm{g})$ was subjected to cDNA synthesis by means of an RNA transcription kit (Thermo Fisher Scientific). Quantitative real-time PCR was performed using the Quantitative SYBR-Green PCR kit (Thermo Fisher Scientific) on the ABI PRISM 7500 Fast system (Applied Biosystems). All experiments were performed as specified according to the manufacturer's protocols. The primers used were as follows: ASNS forward, CTGCACGCCCTCTATGACA and reverse, TAAAAGGCAGCCAATCCTTCT; GAPDH forward, GAA GGTGAAGGTCGGAGTC and reverse, GAAGATGGTGAT GGGATTTC. All samples were analyzed using 3 parallel samples and repeated at least 3 times. The relative expression of the target gene was calculated using $2^{-\Delta \Delta \mathrm{Ct}}$ values with the Application Relative Quantification Study program.

Patients and follow-up. A total of 50 patients with NK/T cell lymphoma at the First Affiliated Hospital of Zhengzhou University from 1 July 2009 to 30 June 2010 were enrolled in the study. The patients were included if they had histologic and immunohistochemical confirmation of NK/T cell lymphoma according to the 2008 World Health Organization criteria (21). Tumor staging was performed according to the Improved Ann Arbor installments. Physical condition scoring criteria used Zubrod-ECOG-WHO (ZPS, 5-point method). The patients who were further subjected to survival analysis had not undergone any previous treatment for lymphoma and received at least one of the following therapies: chemotherapy containing L-Asp (10,000 U/day for days 1-7 every cycle) or PEG-Asp $(4,750 \mathrm{U}$ every cycle) for at least 2 cycles. Paraffin-embedded tumor tissues were available for the patients. Tumor responses were assessed for every two cycles of chemotherapy. Complete response (CR) was defined according to the Revised Response Criteria for Lymphoma (22). The follow-up period was defined as the interval from the date of diagnosis to the date of death or the last follow-up. Patients who died from other causes were treated as censored cases. All patients were observed until July 2013. Overall survival was defined as the interval between the date of diagnosis and death. Progression-free survival (PFS) was defined as the interval between the date of diagnosis and recurrence or progression; if recurrence was not diagnosed, patients were censored at the date of death or the last follow-up. This study was approved by the Ethics Committee of The First Affiliated Hospital of Zhengzhou University and informed consent was obtained from all participants according to the committee's regulations.

Branched DNA-liquidchip technology (bDNA-LCT). bDNALCT of SurExam Bio-Tech Co., Ltd. (Guangzhou, China) was used to detect the ASNS mRNA expression levels in the NK/T cell lymphoma tissues. The paraffin-embedded tissue samples of the patients were lysed. The samples then released the RNA, and the spherical particles in the kit further captured the target RNA. RNA signals were then amplified, and the Luminex system was used to detect the expression of the target mRNA level. The original data obtained by the Multi-Flow Fluorescence Luminex $200^{\mathrm{TM}}$ matrix was detected and uniformly processed. The result was the netMFI ASNS mRNA relative 
Table I. $\mathrm{IC}_{50}$ values for the 7 lymphoma cell lines treated with L-Asp and PEG-asp (mean \pm SD).

\begin{tabular}{lccc}
\hline Cell line & L-asp $(\mathrm{U} / \mathrm{ml})$ & PEG-asp $(\mathrm{U} / \mathrm{ml})$ & P-value \\
\hline YTS & $0.00032 \pm 0.00013$ & $0.00149 \pm 0.00029$ & 0.00300 \\
SNK-6 & $3.48000 \pm 1.33525$ & $4.55000 \pm 0.82504$ & 0.30300 \\
DOHH2 & $12.38466 \pm 2.32507$ & $8.00033 \pm 1.20000$ & 0.04400 \\
Raji & $20.15666 \pm 2.31971$ & $24.0700 \pm 1.69717$ & 0.07800 \\
Hut-78 & - & - & - \\
Jurkat & - & - & - \\
Karpas 299 & - & - & - \\
\hline
\end{tabular}

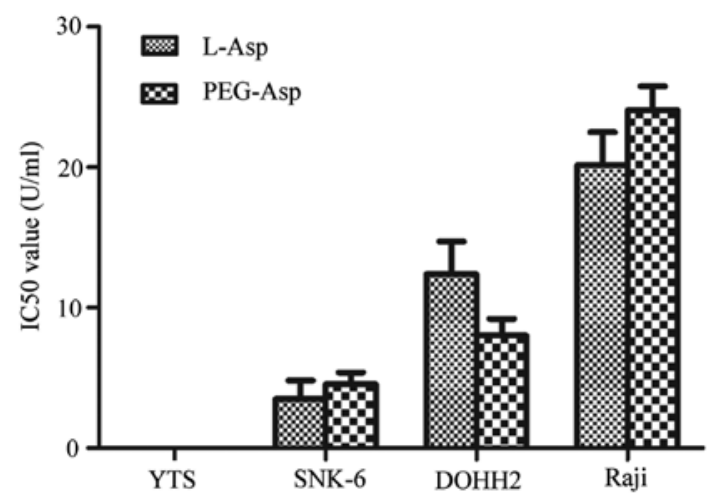

Figure 1. The $\mathrm{IC}_{50}$ values of L-asp and PEG-Asp in 4 lymphoma cell lines.

expression. Based on the median value, the patients were divided accrording to ASNS mRNA expression: the 'high expression group' and the 'low expression group'.

Statistical analysis. All data were processed by SPSS 16.0 software. The experimental data are expressed as mean \pm standard deviation (mean $\pm \mathrm{SD}$ ). Mean values were considered significantly different at $P \leq 0.05$. Pearson's $\chi^{2}$ test or Fisher's exact test was used to analyze the relationship between ASNS expression and the clinicopathological features. Survival curves were calculated using the Kaplan-Meier method and compared using the log-rank test. The Cox proportional-hazard regression model was used for analyses to explore the effect of the clinicopathological variables and ASNS expression on survival, and $\mathrm{P} \leq 0.05$ was considered to indicate a statistically significant result.

\section{Results}

Cell proliferation assays. The MTT assay results showed that the sensitivity of the different lymphoma cell lines to PEG-Asp (for $48 \mathrm{~h}$ ) varied greatly. YTS cells were the most sensitive to the treatment, DOHH2, Raji and SNK-6 cells were relatively more sensitive and Hut-78, Jurkat and Karpas 299 cells were naturally resistant to the treatment. The $\mathrm{IC}_{50}$ values could not be determined for concentrations $>150 \mathrm{U} / \mathrm{ml}$. The $\mathrm{IC}_{50}$ values of 4 cell lines are shown in Table I and Fig. 1.

Comparison of ASNS expression in the lymphoma cell lines before and after treatment with PEG-Asp. Seven cell lines

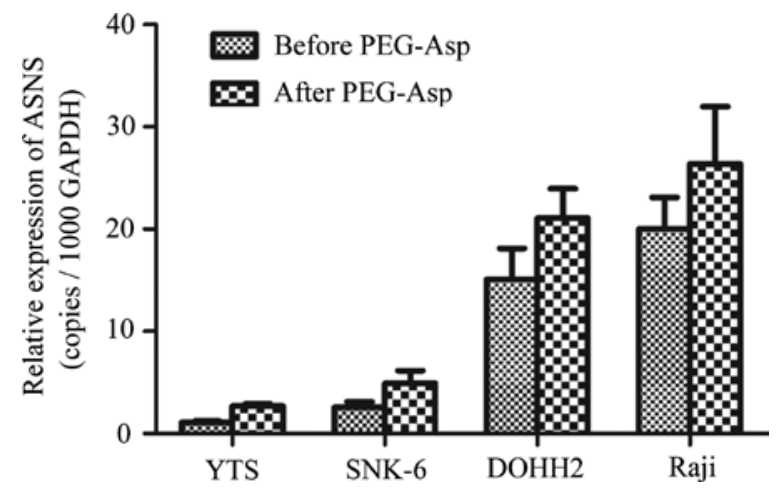

Figure 2. Relative expression levels of ASNS before and after PEG-Asp treatment in 4 lymphoma cell lines.

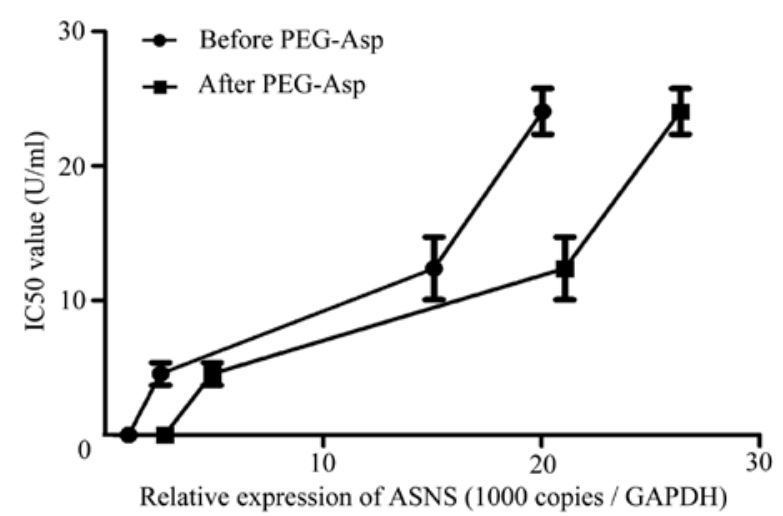

Figure 3. Correlation between ASNS and $\mathrm{IC}_{50}$ value before and after PEG-Asp treatment in 4 lymphoma cell lines.

were treated with PEG-Asp with concentrations at $\mathrm{IC}_{50}$ for 48 h. Hut-78, Jurkat and Karpas 299 cells were naturally resistant to treatment at a concentration of $150 \mathrm{U} / \mathrm{ml}$ PEG-Asp. The expression levels and the differences in expression level of ASNS before and after PEG-Asp treatment are shown in Table II and Fig. 2. The correlation between ASNS expression and the $\mathrm{IC}_{50}$ values of PEG-Asp are presented in Fig. 3. A negative correlation was noted between ASNS expression levels and the sensitivity to PEG-Asp ( $\mathrm{r}=-0.953, \mathrm{P}=0.47)$.

ASNS was weakly expressed in the NK/T cell lymphoma specimens. bDNA-LCT was performed to analyze ASNS mRNA expression in paraffin-embedded tissue samples derived from 50 patients with NK/T cell lymphoma and 12 nasal polyps and chronic rhinitis tissues. The level of ASNS mRNA varied greatly between the tumor tissues and the polyps and rhinitis tissues $(0.480 \pm 0.307$ and $0.739 \pm 0.267 ; \mathrm{P}=0.009)$ (Fig. 4).

Association between ASNS expression and clinicopathological features. We next examined the relationship between the ASNS expression levels in tumor tissues and the clinicopathological characteristics of 50 patients (Table III). Pearson's $\chi^{2}$ test indicated that the expression of ASNS was associated with III-IV tumor stages $(\mathrm{P}=0.041)$ and high International Prognostic Index (IPI) $(\mathrm{P}=0.018)$ in patients with $\mathrm{NK} / \mathrm{T}$ cell lymphoma. Other clinical characteristics were not closely correlated with the expression of ASNS, including age, gender, 
Table II. ASNS expression levels in 7 lymphoma cell lines before and after treatment with PEG-Asp for $48 \mathrm{~h}$ (mean \pm SD, copies/1,000 GAPDH mRNA).

\begin{tabular}{lcccc}
\hline Cell lines & Before treatment & After treatment & t-value & P-value \\
\hline YTS & $1.077 \pm 0.139$ & $2.732 \pm 0.192$ & -25.450 & 0.000 \\
SNK-6 & $2.546 \pm 0.570$ & $4.902 \pm 1.245$ & -4.894 & 0.001 \\
DOHH2 & $15.067 \pm 3.047$ & $21.067 \pm 2.888$ & -3.788 & 0.005 \\
Raji & $20.055 \pm 3.071$ & $26.371 \pm 5.605$ & -3.309 & 0.011 \\
Hut-78 & $30.593 \pm 8.429$ & $41.833 \pm 14.509$ & -2.363 & 0.046 \\
Jurkat & $80.938 \pm 15.372$ & $106.723 \pm 40.533$ & -2.208 & 0.058 \\
Karpas 299 & $220.932 \pm 47.810$ & $808.725 \pm 145.675$ & -10.702 & 0.000 \\
\hline
\end{tabular}

Table III. Correlation of the clinicopathological features of 50 NK/T cell lymphoma cases and ASNS expression.

\begin{tabular}{|c|c|c|c|c|}
\hline \multirow[b]{2}{*}{ Features } & \multicolumn{2}{|c|}{$\begin{array}{c}\text { ASNS } \\
\text { expression }\end{array}$} & \multirow[b]{2}{*}{ P-value } & \multirow[b]{2}{*}{$\chi^{2}$} \\
\hline & Low & High & & \\
\hline Gender & & & 0.208 & 1.587 \\
\hline Male & 20 & 16 & & \\
\hline Female & 5 & 9 & & \\
\hline Age (years) & & & 0.713 & 0.136 \\
\hline$<60$ & 21 & 20 & & \\
\hline$\geq 60$ & 4 & 5 & & \\
\hline ECOG PS & & & 0.773 & 0.117 \\
\hline$<2$ & 20 & 19 & & \\
\hline$\geq 2$ & 5 & 6 & & \\
\hline B symptoms & & & 0.254 & 1.299 \\
\hline Yes & 9 & 13 & & \\
\hline No & 16 & 12 & & \\
\hline LDH & & & 0.747 & 0.104 \\
\hline Normal & 18 & 19 & & \\
\hline Elevated & 7 & 6 & & \\
\hline IPI score & & & $0.018^{\mathrm{a}}$ & 5.556 \\
\hline $0-2$ & 20 & 12 & & \\
\hline $3-4$ & 5 & 13 & & \\
\hline EBER & & & 0.082 & 0.774 \\
\hline Positive & 15 & 14 & & \\
\hline Negative & 10 & 11 & & \\
\hline $\begin{array}{l}\text { Efficacy after } \\
\text { primary therapy }\end{array}$ & & & 0.393 & 0.728 \\
\hline $\mathrm{CR}$ & 17 & 11 & & \\
\hline Non-CR & 8 & 14 & & \\
\hline Ann Arbor stage ${ }^{a}$ & & & $0.041^{\mathrm{a}}$ & 4.160 \\
\hline I-II & 19 & 12 & & \\
\hline III-IV & 6 & 13 & & \\
\hline
\end{tabular}

ECOG PS, Eastern Cooperative Oncology Group performance status; CR, complete response; LDH, lactate dehydrogenase; IPI, International Prognostic Index; EBER, Epstein Barr virus-encoding RNAs. Efficacy after primary therapy, only for the patients who received chemotherapy containing L-Asp or PEG-Asp. ${ }^{\text {a }} \mathrm{P} \leq 0.05$.

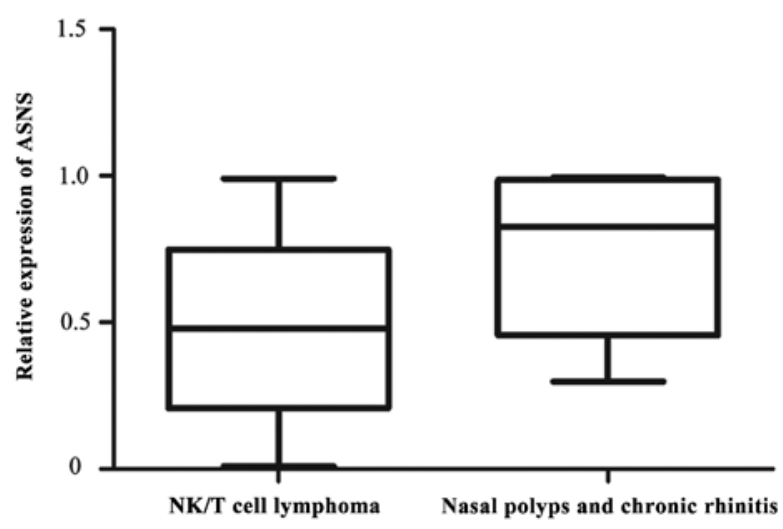

Figure 4. Difference in ASNS expression between NK/T cell lymphoma tissue and nasal polyps and chronic rhinitis tissues.

ECOG performance status, B symptoms, EBER-positivity, serum LDH level, efficacy after primary therapy containing L-Asp or PEG-Asp chemotherapy.

Lack of correlation between ASNS expression level and CR rate. The tumor responses to treatment were assessed for all of the patients who used the chemotherapy regimens containing L-Asp or PEG-Asp by imaging studies based on the International Standard Response criteria for non-Hodgkin's lymphoma. Comparing patients in the high and low ASNS groups, no significant difference was found in the response rate $(\mathrm{P}=0.393)$.

Association of the ASNS expression level with prognosis. The Kaplan-Meier survival curves comparing patients with high ASNS expression and patients with low expression in a group of $36 \mathrm{NK} / \mathrm{T}$ cell lymphoma patients who used chemotherapy regimens containing L-Asp and PEG-Asp are shown in Figs. 5 and 6 . The analysis showed that the mean progression-free survival times in the low ASNS expression group and in the high ASNS expression group were 26.6 months (95\% CI, 21.9-31.3) and 21.2 months (95\% CI, 17.1-25.4), respectively ( $\mathrm{P}=0.031$ ) (Fig. 5). The median overall survival (OS) time was 30.1 months (95\% CI, 25.6-34.5) in the low ASNS expression group, whereas it was 24.3 months (95\% CI, 19.6-28.9) in the high ASNS expression group ( $\mathrm{P}=0.033$; Fig. 6).

Univariate analysis and multivariate Cox regression were used to analyze whether ASNS expression and other clinical 
Table IV. Unvariate and multivariate analysis for OS.

\begin{tabular}{|c|c|c|c|c|c|c|}
\hline \multirow[b]{2}{*}{ Characteristics } & \multicolumn{3}{|c|}{ Unvariate analysis } & \multicolumn{3}{|c|}{ Multivariate analysis } \\
\hline & HR & CI $(95 \%)$ & $\mathrm{P}$-value & HR & CI $(95 \%)$ & $\mathrm{P}$-value \\
\hline ASNS expression & 2.426 & $1.031-5.704$ & $0.042^{\mathrm{a}}$ & 2.901 & $1.155-7.283$ & $0.023^{\mathrm{a}}$ \\
\hline Gender & 1.174 & $0.496-2.774$ & 0.715 & & & \\
\hline Age & 2.366 & $0.718-7.167$ & 0.128 & & & \\
\hline ECOG PS & 1.668 & $0.614-4.531$ & 0.316 & & & \\
\hline B symptoms & 0.571 & $0.249-1.311$ & 0.186 & & & \\
\hline $\mathrm{LDH}$ & 3.361 & $1.357-8.323$ & $0.009^{\mathrm{a}}$ & 5.067 & $1.796-14.291$ & $0.002^{\mathrm{a}}$ \\
\hline Ann Arbor stage & 1.667 & $0.710-3.914$ & 0.241 & & & \\
\hline IPI score & 2.687 & $1.003-6.991$ & $0.043^{\mathrm{a}}$ & 0.303 & $0.617-4.742$ & 0.303 \\
\hline EBER & 1.901 & $0.770-4.692$ & 0.163 & & & \\
\hline $\mathrm{CR}$ rate & 5.545 & $2.114-14.548$ & $0.000^{\mathrm{a}}$ & 6213 & $2.250-17.154$ & $0.000^{\mathrm{a}}$ \\
\hline
\end{tabular}

HR, hazard ratio; CI, confidence interval; ECOG PS, Eastern Cooperative Oncology Group performance status; CR, complete response; LDH, lactate dehydrogenase; IPI, International Prognostic Index; EBER, Epstein Barr virus-encoding RNAs. Statistical significance, ${ }^{\mathrm{P} P \leq 0.05 .}$

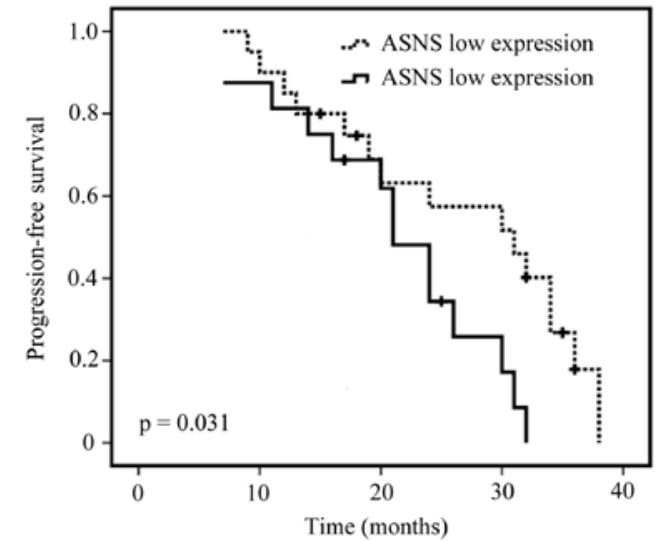

Figure 5. Kaplan-Meier curves for time to progression-free survival of patients with high and low ASNS levels.

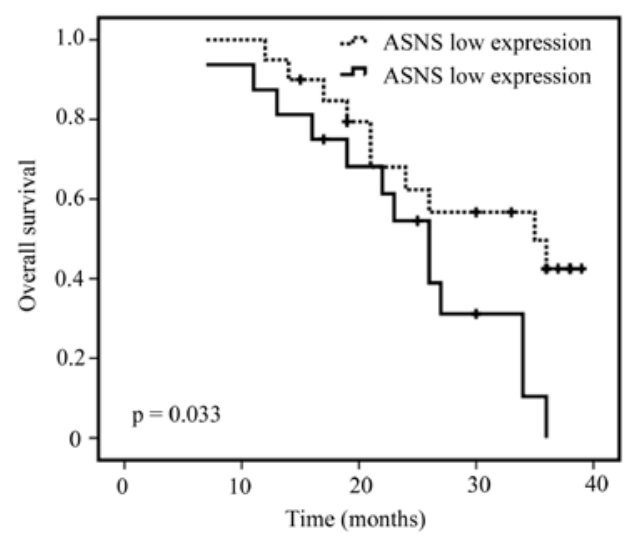

Figure 6. Kaplan-Meier curves for time to the overall survival of patients with high and low ASNS levels.

parameters could be independent prognostic factors for NK/Tcell lymphoma. A total of 10 parameters were analyzed with unvariate analysis. No significant correlations between OS and a number of clinicopathological parameters, including gender ( $\mathrm{P}=0.715)$, age $(\mathrm{P}=0.128)$, ECOG $\mathrm{PS}(\mathrm{P}=0.316)$, B symptoms $(\mathrm{P}=0.186)$, Ann Arbor stage $(\mathrm{P}=0.241)$, EBER $(\mathrm{P}=0.163)$ were noted, while 4 factors, ASNS expression level $(\mathrm{P}=0.033)$, $\mathrm{LDH}$ $(\mathrm{P}=0.009)$, IPI score $(\mathrm{P}=0.043)$ and $\mathrm{CR}$ after primary treatment $(\mathrm{P}<0.001)$ displayed a correlation with OS at varying degrees. These four individual parameters were further subjected to multivariate Cox proportional hazards model, which demonstrated that LDH $(\mathrm{P}=0.002)$, efficacy of primary therapy $(\mathrm{P}<0.001)$ and ASNS expression level $(\mathrm{P}=0.023)$ were also identified as independent prognostic factors for OS (Table IV).

\section{Discussion}

In the present study, we demonstrated for the first time the expression patterns and prognostic value of ASNS mRNA in NK/T cell lymphoma, including cell lines and clinical samples. We also demonstrated the downregulation of ASNS at the mRNA level in the NK/T cell lymphoma tissues when compared with the levels in chronic rhinitis and nasal polyps using bDNA-LCT. Our findings showed that expression of ASNS was linked strongly with the sensitivity to L-Asp and PEG-Asp treatment and to prognostic factors, including III-IV stage, Ann Arbor stage, high IPI scores, but not with efficacy after primary therapy containing PEG-Asp or L-Asp. The Kaplan-Meier analysis showed that patients with NK/T cell lymphoma who had low ASNS expression in general had a better prognosis than those with high ASNS expression. Multivariate analysis revealed that the ASNS expression level might be a significant prognostic indicator affecting survival after chemotherapy containing PEG-Asp or L-Asp.

The cells that expressed low ASNS protein levels were more sensitive to L-Asp treatment probably because they produce less asparagine and are, therefore, more dependent on extracellular asparagine to meet metabolic demands. Yet, the mRNA expression level of ASNS does not necessarily correlate with protein level and enzyme activity of ASNS. However, Hutson et al (23) confirmed that the mRNA level 
corresponded to protein and activity levels. In a previous study, it was reported that most types of tumors, particularly leukemia and lymphoma, lack activity of ASNS (24). Although ASNS mRNA analysis led to variable conclusions regarding the relationship between ASNS mRNA levels in primary ALL cells and L-Asp sensitivity, in the present study, we confirmed that there is some relationship between ASNS mRNA expression and the sensitivity to PEG-Asp in vitro. Moreover, recent research suggests that the expression level of ASNS in cell lines can better reflect the sensitivity to L-Asp, while in clinical specimens the results have been questionable (25). Previous studies on pediatric ALL showed that ASNS mRNA expression was linked with L-Asp resistance only in TEL-AML1-negative but not TEL-AML1-positive ALL. TEL-AML1-positive ALL patients were more sensitive to L-Asp compared with TEL-AML1-negative patients, although the former had a relative high level of ASNS (26), and also high expression of ASNS was associated with poor prognosis compared with low expression in TEL-AML1-negative but not in TEL-AML1-positive B-lineage ALL (27). Therefore, the ASNS level alone does not determine sensitivity to L-Asp at least in some subtypes of hematological malignancies. Thus, it is generally accepted that the role of ASNS in leukaemic cells with regard to L-Asp resistance may vary among genetic subtypes (26-28). In the present study, we also came to the same conclusion that no correlation was found between the ASNS expression level and CR rate. This could also be due to the relatively small number of patients and the varied chemotherapy regimens except L-Asp. What is more, for NK/T cell lymphoma, we did not examine the genetic aberrations, and whether there is a potential relationship between gene fusion or other subtypes of aberrations and ASNS expression.

Pancreatic and ovarian tumors and HCC with low ASNS expression levels have also been proposed for L-Asp therapy $(17,20,29)$. In addition, one study revealed that this drug has an antiproliferative effect in $\beta$-catenin-mutated HepG 2 cells (30). This result extends the findings of those from previous studies on pancreatic and ovarian tumors and HCC indicating that ASNS may be a potential therapeutic target in the treatment of NK/T cell lymphoma. Based on the severe side-effects of this drug, such as pancreatitis and allergic reactions, it is necessary to stratify patients based on the ASNS expression level in the tumor. Low expression of ASNS identified by bDNA-LCT might be an early warning sign that patients should be closely monitored and receive chemotherapy containing L-Asp or PEG-Asp. It has been proposed that NK/T cell lymphoma patients with low ASNS expression levels may benefit more from treatment with L-Asp, which can also alleviate the adverse effect and economic burden of patients with high ASNS expression.

How the ASNS gene affects prognosis is an important issue. One reason is that the expression level of ASNS has a certain relationship with the sensitivity to L-Asp. A high expression level of ASNS indicates that these patients are more likely to be resistant to chemotherapy regimens containing L-Asp or PEG-Asp. Therefore, they may not easily achieve complete remission which will affect long-term prognosis. On the other hand, Greco et al (31) and Gong and Basilico (32) determined that ASNS could complement temperature-sensitive hamster BHK ts11 cells, which are specifically blocked in progressing through the G1 phase of the cell cycle when grown at a nonpermissive temperature. This loss in ASNS activity leads to cell cycle arrest, as a consequence of a depletion of cellular asparagine, and a corresponding increase in ASNS mRNA due to regulatory mechanisms. Thus, we conclude that the ASNS gene plays a critical role in the regulation of the cell cycle. A high level of ASNS results in cell cycle dysregulation in tumors. Thus, it may have specific impact on the malignant phenotype of tumors. Accordingly it may have an effect on the prognosis of NK/T cell lymphoma patients. Activation of the GCN2-eIF2-ATF4 signaling pathway, leading to increased ASNS expression, appears to be a component of solid tumor adaptation to nutrient deprivation and/or hypoxia, so that ASNS function extends beyond asparagine biosynthesis (24). There is also evidence suggesting that ASNS is important in certain metastatic mechanisms. When cancer spreads from the primary tumor to distant sites, cells enter into the bloodstream and exist in suspension until they reach a metastatic site. Patrikainen et al (33) and Ameri et al (34) observed that PC-3 prostate cancer cells and human MDA-MB-231 breast cancer cells which have a strong potential for distant metastasis and an increased capacity for colony formation exhibit an elevated expression of ASNS. Its increased abundance in metastasizing cells suggests that ASNS activity is beneficial for cancer cell survival once they detach from the primary tumor and enter the bloodstream. Patients with high ASNS expression are more susceptible to tumors than patients with low ASNS expression and have a tendency to develop distant metastasis thus are rendered with a malignant phenotype.

In conclusion, the present study explored the effects of ASNS on the drug sensitivity and prognosis in NK/T cell lymphoma patients for the first time. High ASNS expression is associated with a poorer performance at diagnosis and a less favorable long-term outcome. Based on these results, low ASNS expression may be used to select patients for treatment with L-Asp or PEG-Asp-containing chemotherapy regimens. In addition, an alternative therapeutic strategy for patients with low ASNS expression was also addressed.

\section{Acknowledgements}

The present study was supported by the National Natural Science Foundation of China (81172118).

\section{References}

1. Aozasa K, Ohsawa M, Tajima K, Sasaki R, Maeda H, Matsunaga T and Friedmann I: Nation-wide study of lethal mid-line granuloma in Japan: frequencies of wegener's granulo matosis, polymorphic reticulosis, malignant lymphoma and other related conditions. Int J Cancer 44: 63-66, 1989.

2. Kim GE, Cho JH, Yang WI, Chung EJ, Suh CO, Park KR, Hong WP, Park IY, Hahn JS, Roh JK and Kim BS: Angiocentric lymphoma of the head and neck: patterns of systemic failure after radiation treatment. J Clin Oncol 18: 54-63, 2000.

3. Lee J, Park YH, Kim WS, Lee SS, Ryoo BY, Yang SH, Park KW, Kang JH, Park JO, Lee SH, Kim K, Jung CW, Park YS, Im YH, Kang WK, Lee MH, Ko YH, Ahn YC and Park K: Extranodal nasal type NK/T-cell lymphoma: elucidating clinical prognostic factors for risk-based stratification of therapy. Eur J Cancer 41: 1402-1408, 2005

4. Egger G, Liang G, Aparicio A and Jones PA: Epigenetics in human disease and prospects for epigenetic therapy. Nature 429: $457-463,2004$ 
5. Kim TM, Park YH, Lee SY, Kim JH, Kim DW, Im SA Kim TY, Kim CW, Heo DS, Bang YJ, Chang KH and Kim NK: Local tumor invasiveness is more predictive of survival than International Prognostic Index in stage I(E)/II(E) extranodal NK/T-cell lymphoma, nasal type. Blood 106: 3785-3790, 2005.

6. Lee J, Suh C, Park YH, Ko YH, Bang SM, Lee JH, Lee DH, Huh J, Oh SY, Kwon HC, Kim HJ, Lee SI, Kim JH, Park J, Oh SJ, Kim K, Jung C, Park K and Kim WS: Extranodal natural killer T-cell lymphoma, nasal-type: a prognostic model from a retrospective multicenter study. J Clin Oncol 24: 612-618, 2006.

7. Yamaguchi M: Current and future management of NK/T-cell lymphoma based on clinical trials. Int J Hematol 96: 562-571, 2012.

8. Ueno T, Ohtawa K, Mitsui K, Kodera Y, Hiroto M, Matsushima A, Inada $\mathrm{Y}$ and Nishimura $\mathrm{H}$ : Cell cycle arrest and apoptosis of leukemia cells induced by L-asparaginase. Leukemia 11: 1858-1861, 1997.

9. Richards NG and Schuster SM: Mechanistic issues in asparagine synthetase catalysis. Adv Enzymol Relat Areas Mol Biol 72: 145-198, 1998

10. Chen H, Pan YX, Dudenhausen EE and Kilberg MS: Amino acid deprivation induces the transcription rate of the human asparagine synthetase gene through a timed program of expression and promoter binding of nutrient-responsive bZIP transcription factors as well as localized histone acetylation. J Biol Chem 279: 50829-50839, 2004.

11. Kilberg MS, Pan YX, Chen H and Leung-Pineda V: Nutritional control of gene expression: how mammalian cells respond to amino acid limitation. Annu Rev Nutr 25: 59-85, 2005.

12. Li BS, Gu LJ, Luo CY, Li WS, Jiang LM, Shen SH, Jiang H, Shen SH, Zhang B, Chen J, Xue HL and Tang JY: The downregulation of asparagine synthetase expression can increase the sensitivity of cells resistant to L-asparaginase. Leukemia 20 : 2199-2201, 2006.

13. Hashimoto K, Suzuki F and Sakagami H: Declined asparagine synthetase mRNA expression and enhanced sensitivity to asparaginase in HL-60 cells committed to monocytic differentiation. Anticancer Res 29: 1303-1308, 2009.

14. Aslanian AM, Fletcher BS and Kilberg MS: Asparagine synthetase expression alone is sufficient to induce L-asparaginase resistance in MOLT-4 human leukaemia cells. Biochem J 357: 321-328, 2001

15. Zwaan CM, Kaspers GJ, Pieters R, Hahlen K, Janka-Schaub GE, van Zantwijk CH, Huismans DR, de Vries E, Rots MG, Peters GJ, Jansen G, Creutzig U and Veerman AJ: Different drug sensitivity profiles of acute myeloid and lymphoblastic leukemia and normal peripheral blood mononuclear cells in children with and without Down syndrome. Blood 99: 245-251, 2002.

16. Lorenzi PL, Llamas J, Gunsior M, Ozbun L, Reinhold WC, Varma S, Ji H, Kim H, Hutchinson AA, Kohn EC, Goldsmith PK, Birrer MJ and Weinstein JN: Asparagine synthetase is a predictive biomarker of L-asparaginase activity in ovarian cancer cell lines. Mol Cancer Ther 7: 3123-3128, 2008.

17. Lorenzi PL, Reinhold WC, Rudelius M, Gunsior M, Shankavaram U, Bussey KJ, Scherf U, Eichler GS, Martin SE, Chin K, Gray JW, Kohn EC, Horak ID, Von Hoff DD, Raffeld M, Goldsmith PK, Caplen NJ and Weinstein JN: Asparagine synthetase as a causal, predictive biomarker for L-asparaginase activity in ovarian cancer cells. Mol Cancer Ther 5: 2613-2623, 2006.

18. Cui H, Darmanin S, Natsuisaka M, Kondo T, Asaka M, Shindoh M, Higashino F, Hamuro J, Okada F, Kobayashi M, Nakagawa $\mathrm{K}$ and Koide H: Enhanced expression of asparagine synthetase under glucose-deprived conditions protects pancreatic cancer cells from apoptosis induced by glucose deprivation and cisplatin. Cancer Res 67: 3345-3355, 2007.
19. Sircar K, Huang H, Hu L, Cogdell D, Dhillon J, Tzelepi V, Efstathiou E, Koumakpayi IH, Saad F, Luo D, Bismar TA, Aparicio A, Troncoso P, Navone $\mathrm{N}$ and Zhang W: Integrative molecular profiling reveals asparagine synthetase is a target in castration-resistant prostate cancer. Am J Pathol 180: 895-903, 2012.

20. Zhang B, Dong LW, Tan YX, Zhang J, Pan YF, Yang C, Li MH, Ding ZW, Liu LJ, Jiang TY, Yang JH and Wang HY: Asparagine synthetase is an independent predictor of surgical survival and a potential therapeutic target in hepatocellular carcinoma. $\mathrm{Br} \mathrm{J}$ Cancer 109: 14-23, 2013.

21. Swerdlow SH, Campo E, Harris NL, Jaffe ES, Pileri SA, Stein $\mathrm{H}$, Thiele $\mathrm{J}$ and Vardiman JWL: WHO Classification of Tumours of Haematopoietic and Lymphoid Tissue (IARC WHO Classification of Tumours). IARC Press, Lyon, 2008.

22. Cheson BD, Pfistner B, Juweid ME, Gascoyne RD, Specht L, Horning SJ, Coiffier B, Fisher RI, Hagenbeek A, Zucca E et al; International Harmonization Project on Lymphoma: Revised response criteria for malignant lymphoma. J Clin Oncol 25: 579-586, 2007

23. Hutson RG, Kitoh T, Moraga Amador DA, Cosic S, Schuster SM and Kilberg MS: Amino acid control of asparagine synthetase: relation to asparagi-nase resistance in human leukemia cells. Am J Physiol 272: 1691-1699, 1997.

24. Balasubramanian MN, Butterworth EA and Kilberg MS: Asparagine synthetase: regulation by cell stress and involvement in tumor biology. Am J Physiol Endocrinol Metab 304: 789-799, 2013.

25. Fine BM, Kaspers GJ, Ho M, Loonen AH and Boxer LM: A genome-wide view of the in vitro response to L-asparaginase in acute lymphoblastic leukemia. Cancer Res 65: 291-299, 2005.

26. Stams WA, den Boer ML, Beverloo HB, Meijerink JP, Stigter RL, van Wering ER, Janka-Schaub GE, Slater R and Pieters R: Sensitivity to L-asparaginase is not associated with expression levels of asparagine synthetase in $\mathrm{t}(12 ; 21)^{+}$pediatric ALL. Blood 101: 2743-2747, 2003.

27. Stams WA, den Boer ML, Holleman A, Appel IM, Beverloo HB, van Wering ER, Janka-Schaub GE, Evans WE and Pieters R: Asparagine synthetase expression is linked with L-asparaginase resistance in TEL-AML1-negative but not TEL-AML1-positive pediatric acute lymphoblastic leukemia. Blood 105: 4223-4225, 2005.

28. Den Boer ML, Evans WE and Pieters R: TEL-AML1-positive ALL: a discordant genotype. Cell Cycle 4: 997-998, 2005.

29. Dufour E, Gay F, Aguera K, Scoazec JY, Horand F, Lorenzi PL and Godfrin Y: Pancreatic tumor sensitivity to plasma L-asparagine starvation. Pancreas 41: 940-948, 2012.

30. Tardito S, Chiu M, Uggeri J, Zerbini A, Da Ros F, Dall'Asta V, Missale G and Bussolati O: L-Asparaginase and inhibitors of glutamine synthetase disclose glutamine addiction of betacatenin-mutated human hepatocellular carcinoma cells. Curr Cancer Drug Targets 11: 929-943, 2011.

31. Greco A, Gong SS, Ittmann M and Basilico C: Organization and expression of the cell cycle gene, ts11, that encodes asparagine synthetase. Mol Cell Biol 9: 2350-2359, 1989.

32. Gong SS and Basilico C: A mammalian temperature-sensitive mutation affecting G1 progression results from a single amino acid substitution in asparagine synthetase. Nucleic Acids Res 18: 3509-3513, 1990.

33. Patrikainen L, Porvari K, Kurkela R, Hirvikoski P, Soini Y and Vihko P: Expression profiling of PC-3 cell line variants and comparison of MIC-1 transcript levels in benign and malignant prostate. Eur J Clin Invest 37: 126-133, 2007.

34. Ameri K, Luong R, Zhang H, Powell AA, Montgomery KD, Espinosa I, Bouley DM, Harris AL and Jeffrey SS: Circulating tumour cells demonstrate an altered response to hypoxia and an aggressive phenotype. Br J Cancer 102: 561-569, 2010. 